\title{
Experimental study on the performance of emulsions produced during ASP flooding
}

\author{
Ahmed B. Laben ${ }^{1} \cdot$ Hussain H. Al- Kayiem ${ }^{2} \cdot$ Mohammed A. Alameen ${ }^{3}$ Javed A. Khan ${ }^{2} \cdot$ Ahmed F. Belhaj $^{4}$. \\ Khaled A. Elraies ${ }^{3}$
}

Received: 7 September 2021 / Accepted: 27 November 2021 / Published online: 8 December 2021

(c) The Author(s) 2021

\begin{abstract}
ASP (Alkaline/Surfactant/Polymer) flooding is one of the most promising techniques that has proven to have successful application in several laboratory and pilot tests. However, the formation of persistent and stable emulsions is one of the associated problems with ASP flooding. The present work investigated the effect of sodium carbonate alkaline, Alpha Olefin Sulfonate (AOS) surfactant, and GLP100 polymer on produced crude oil emulsion. The study was conducted by measuring the emulsion stability in terms of water separation and rag layer volume using a TurbiScan analyzer, the dispersed droplet size using cross-polarization microscopy, the interfacial tension using spinning drop tensiometer, and rheological properties using rheometer. The experimental results have shown that AOS presence increased the emulsion stability only when its concentration is above $100 \mathrm{ppm}$. Meanwhile, below $100 \mathrm{ppm}$, the presence of AOS promoted water separation and reduced the rag layer volume. In a less significant manner, a high concentration of sodium carbonate alkali increased the stability of the emulsion. The use of GLP100 Polymer has shown substantial ability in promoting water separation and reducing the rag layer volume to a minimal level. It is believed that the outcomes of this work will aid in developing a suitable destabilization process to enhance the oil-water separation and produced water treatment from ASP flooding in the oil production fields. Further investigations on AS, AP, SP as well as the ASP's combined effect on emulsion stability, droplet size, interfacial tension and rheological properties are highly recommended to support the decision-makers on the EOR implementations with chemical additives.
\end{abstract}

Keywords Alkaline/surfactant/polymer (ASP) $\cdot$ Crude oil $\cdot$ Emulsion stability $\cdot$ EOR $\cdot$ IFT $\cdot$ Rag layer

\section{Introduction}

Hussain H. Al- Kayiem

hussain_kayiem@utp.edu.my

Ahmed F. Belhaj

ahmed.belhaj@ucalgary.ca

1 TAC CONTRACTS PTE LTD, 20 Ang Mo Kio Industrial Park 2A, Singapore 567761, Singapore

2 Mechanical Engineering Department, Universiti Teknologi Petronas, 32610 Perak, Seri Iskandar, Malaysia

3 Petroleum Engineering Department, Universiti Teknologi Petronas, 32610 Perak, Seri Iskandar, Malaysia

4 Department of Chemical and Petroleum Engineering, Schulich School of Engineering, University of Calgary, Calgary, AB T2N 1N4, Canada
The increasing demand for crude oil and the declining number of new oil fields discoveries have imposed a need to apply new recovery technologies to extract additional oil (Belhaj et al. 2019a; Saxena et al. 2019). Over the years, enhanced oil recovery (EOR) processes have been developed to recover additional trapped oil from the remaining oil in the developed reservoirs (Yekeen et al. 2019). Compared to other EOR techniques, chemical flooding appears to be more effective and economic (Belhaj et al. 2019b; Li et al. 2019). For a mature water flooding, the capillary number is usually in the range of $10^{-7}$ to $10^{-6}$, which is considered insufficient to recover a sufficient oil volume; thus, a great deal of residual oil remains behind (Ahmed and Khaled 2018). Therefore, a higher capillary means more residual oil recovery after the water flooding process (Kang et al. 2020). The utilization of chemical enhanced oil Recovery (CEOR) contributes to

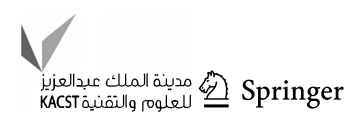


increasing the capillary number, which will result in reducing the residual oil saturation (Pal et al. 2019). CEOR is a type of EOR used to increase oil recovery by injecting alkali (A), surfactant (S), polymer (P) or a combination of the chemicals such as, SP or ASP (Belhaj et al. 2021a; Sheng 2011). In recent years, several ASP projects were reported from oilfields in different countries. It has been surveyed that the ASP flooding is adopted for EOR in 87 fields worldwide. Seventy-four projects are reported in the US, three projects in China and Indonesia, two projects in France and Romania, and one project Germany, UK, and Russia (Riswati et al. 2019; Sheng 2015; Al-Shuaili et al. 2016; Fortenberry et al. 2016; Onyekonwu and Akaranta 2016; Rohilla et al. 2016). In ASP flooding, surfactants reduce the interfacial tension (IFT) between the injected water and trapped oil, therefore, mobilizing the residual oil from its pores (Sayed et al. 2019). Meanwhile, alkalis reduce the surfactant adsorption on the rock and assist in further reducing IFT to ultralow level by producing in-situ surfactant (soap) through a chemical reaction between the alkali and the organic acids existing in the reservoir. Polymers increase the injection water viscosity, making it a key in mobility control, leading to improved sweep efficiency (Sheng 2014). ASP flooding has proven to increase oil recovery up to $20 \%$ OOIP after waterflooding (Kang and Wang 2001; Olsen et al. 1990).

One of the associated problems with ASP flooding is the formation of stable emulsions (Weatherill 2009). Emulsion formation induces many operational problems such as pressure drop in flow lines, difficulty in producing water treatment and water-oil separation (Sheng 2014). The problem of separating water from crude oil is known since the beginning of the oil industry. An emulsion is a system in which the droplets of one liquid are dispersed immiscibly in another continuous liquid phase. The crude oil emulsion is typically a dispersion of water and oil caused by excessive turbulence throughout the production system (Belhaj et al. 2020a; Khatri et al. 2011). Most of the produced emulsions in oilfields are water-in-oil (W/O) emulsions, a dispersion of water droplets in oil. However, other emulsion types are also experienced in oilfields, such as oil-in-water $(\mathrm{O} / \mathrm{W})$ emulsion and multiple emulsions of water-in-oil-inwater $(\mathrm{W} / \mathrm{O} / \mathrm{W})$ and oil-in-water-in-oil $(\mathrm{O} / \mathrm{W} / \mathrm{O})$ emulsion (Sheng 2014). Generally, the emulsion is thermodynamically unstable, i.e., the phases comprising it tend to revert to the original and stable state of being immiscible and separate phases (Kang et al. 2012). The stability of the emulsion is increased when a surface-active agent (i.e., emulsifier) is present in the emulsion system. Emulsifiers such as asphaltene, wax, and resins are present naturally in crude oil. They tend to stabilize the emulsion by forming an interfacial film on the dispersed droplets hindering their coalescence (Sjoblom 2005). In ASP flooding, the injected chemical components tend to be produced with oil and water, increasing the emulsion stability (Jeirani et al. 2014). The emulsion behavior changes as the type and concentration of emulsifiers change and the properties of water and crude oil (Sheng 2010). Various alkali was used for CEOR techniques. In the laboratory tests concerning the chemical selection for EOR injection at the field, $\mathrm{NaOH}$ and $\mathrm{Na}_{2} \mathrm{CO}_{3}$ were tested and yielded better results; and therefore selected for the CEOR pilot test (Ibrahim et al. 2006; Belhaj et al. 2020d; Othman et al. 2007). However, there seemed to be a shift of interest from sodium-based to ammonia-based alkali in recent years. Sharma et al. (2016) recommended $\mathrm{NH}_{4} \mathrm{OH}$ as an alternative alkali for ASP processes transportation and storage advantages. Kusumah and Vazquez (2017) found that $\mathrm{NH}_{4} \mathrm{OH}$ would only require $9 \%$ of the storage required for $\mathrm{Na}_{2} \mathrm{CO}_{3}$ to achieve the same $\mathrm{pH}$ value. These findings agree with Southwick et al. (2016), although there was a concern about health safety and environmental issues that need further study.

The contribution of alkaline/Surfactant/Polymer to the stability of produced crude oil emulsions is neither fully understood nor thoroughly investigated. However, there have been reports from previous projects that implicate riskproduced water treatment. A study by Khan et al. (2015) focused on water in oil (W/O) emulsions imposed by ASP flooding for an EOR field in Malaysia to understand the stability of the emulsion layer under typical process conditions. Another group of researchers (Kalra et al. 2012) have attempted to present the rheology of the problematic water in oil emulsion produced at the facility site. They stated that oil production is generally a complicated multiphase flow inside pipelines. Possible water-in-oil (W/O) emulsions present with other usual phases such as free water and free oil. The W/O emulsions formed can present significant hurdles in production facilities for pumping fluids and during pipeline transport. It is well known that high shear rates provided by pumps, chokes, or valves result in stable emulsion behavior for a field in primary production. Kalra et al. (2012) also reported that understanding W/O-emulsion rheology in ASP-injection oil recovery was essential for the design of pumps and pipelines and handling flow-assurance issues. The formation of a W/O emulsion with chemical injection is a renowned problem on the facility side, as it stabilizes the emulsion (Dalmazzone et al. 2012).

The present study is performed as a recommendation from previous research work associated with the crude emulsion treatment problem and extra water handling of an offshore Malaysian field. Sabzabadi et al. (2013) reported that the facility site of that field is experiencing fluid transport problems due to water production in oil emulsion. This offshore Malaysian field is slated to be the first in the world for Alkaline/Surfactant/Polymer (ASP) chemical flooding via a floating structure in an offshore environment. In continuation of the facility problem due to water in oil emulsion in 
this offshore Malaysian field, the present study is carried out with the actual breakthrough of alkali/surfactant and polymer in the primary separator. The objective of this study is to determine the stabilization of produced crude oil emulsion at various low concentrations of ASP as EOR chemicals. This work was carried out to investigate the impact of varying percentages of ASP components on the separation process. Experimental measurements have been made to study the effectiveness of EOR chemicals on the separation of $40 \%$ of water cut emulsion, with ten different combinations of ASP emulsion. First, the indigenous components of the crude oil in terms of emulsion stability were characterized. Each emulsion with the chemical compound added, i.e., ASP, was characterized by its effect on emulsion stability and droplet size. The experimental investigations focused on the water in oil emulsions imposed by different ASP flooding compositions. In addition, the ability of the polymer concentration on the viscosity of emulsion has been explored. Droplet size distribution has been used to analyze and predict the effectiveness of each individual and combined additives on the stabilization of the emulsion.

\section{Experimental procedure}

\section{Materials}

The crude oil used in this study was obtained from an identified oilfield in Malaysia. Table 1 shows the physical and chemical properties of the crude oil sample. These parameters were characterized at ambient pressure and $60^{\circ} \mathrm{C}$ temperature. The brine water was prepared in UTP laboratory based on the field-produced water properties provided by PETRONAS Research Sdn. Bhd. (PRSB). The composition of the produced water is given in Table 2 . All the chemicals
Table 2 Brine properties

\begin{tabular}{ll}
\hline Chemical compound & $\begin{array}{l}\text { Concentra- } \\
\text { tion }(\mathrm{g} / \mathrm{L})\end{array}$ \\
\hline $\mathrm{CaCl}_{2}\left(\mathrm{H}_{2} \mathrm{O}\right)_{2}$ & 0.8153 \\
$\mathrm{MgCl}_{2}\left(\mathrm{H}_{2} \mathrm{O}\right)_{6}$ & 0.7517 \\
$\mathrm{NaCl}$ & 9.2734 \\
$\mathrm{SrCl}_{2}\left(\mathrm{H}_{2} \mathrm{O}\right)_{6}$ & 0.0296 \\
$\mathrm{KCl}$ & 0.4238 \\
$\mathrm{NaHCO}_{3}$ & 7.1593 \\
$\mathrm{Na}_{2} \mathrm{SO}_{4}$ & 0.5172 \\
\hline
\end{tabular}

were A.R. grade obtained from Sigma-Aldrich and used without further processing.

For this study, the crude oil used was supplied from the oil field. Alkali solution used is Sodium Carbonate $\left(\mathrm{Na}_{2} \mathrm{CO}_{3}\right)$ solution with a stock concentration of 50,000 ppm. Anionic Alpha Olefin Sulfonate (AOS) surfactant at a stock concentration of 10,000 ppm, with a structural formula $\mathrm{RCH}$ (OH) $\left(\mathrm{CH}_{2}\right) \mathrm{n} \mathrm{SO}_{3} \mathrm{Na}$ was used. The polymer used is inhouse GLP100 produced at a stock concentration of $0.1 \%$ $(1000 \mathrm{ppm})$. The polymer is anionic hydrolyzed polyacrylamide with 16 (million Dalton) molecular weight. The client provided the crude oil sample and stock chemicals. The $\mathrm{pH}$ value (1.0\% aq. solution) is in the range of 9.5-11.5. The experiments were carried out at $60{ }^{\circ} \mathrm{C}$.

\section{Preparation of emulsion}

A total of 10 emulsion samples were prepared to investigate the effect of the chemicals: alkaline (A), surfactant (S), and polymer (P) separately on water separation and rag layer volumes. The emulsion samples were prepared by mixing equal volumes of oil and synthetic produced water with different concentrations of the chemicals, as shown in Table 3 .

Table 1 Physical and chemical properties of crude oil

\begin{tabular}{lll}
\hline Physical properties & & \\
\hline Property & Units & Value \\
\hline Density & $\mathrm{g} / \mathrm{cc}$ & 0.79 \\
Viscosity & $\mathrm{cp}$ & 0.4 \\
API gravity & ${ }^{\circ} \mathrm{API}$ & 42 \\
Wax content & $\mathrm{wt} \%$ & 18.82 \\
Total acid number & $\mathrm{mg} \mathrm{KOH} \mathrm{g}{ }^{-1}$ & 0.19 \\
\hline Chemical contents & & 0.69 \\
\hline Asphaltenes & wt $\%$ & 22.52 \\
Saturates & wt $\%$ & 10.38 \\
Aromatics & wt $\%$ & 1.67 \\
Resins & wt $\%$ & \\
\hline
\end{tabular}


Table 3 Chemical concentration for base case samples

\begin{tabular}{llll}
\hline Case & \multicolumn{2}{l}{ Composition $(\mathrm{ppm})$} & \\
\cline { 2 - 4 } & Alkaline & Surfactant & Polymer \\
\hline 1 & 0 & 0 & 0 \\
2 & 250 & 0 & 0 \\
3 & 500 & 0 & 0 \\
4 & 750 & 0 & 0 \\
5 & 0 & 100 & 0 \\
6 & 0 & 200 & 0 \\
7 & 0 & 300 & 0 \\
8 & 0 & 0 & 400 \\
9 & 0 & 0 & 500 \\
10 & 0 & 0 & 600 \\
\hline
\end{tabular}

Previously, (Al-Kayiem and Khan 2017; Khan et al. 2019) have carried out experimental studies on the impact of ASP on crude emulsion stabilization, but the concentration of chemicals is higher compared to the low concentrations adopted in the current research. The present study was performed at a minimum possible concentration of the chemical that breaks through in the primary separator. The mixture was prepared using a digital disperser at $12,000 \mathrm{rpm}$ for $2 \mathrm{~min}$. The samples were then poured into the test tube attached with the TurbiScan stability analyzer. Using the TurbiScan, the emulsion stability was measured as a function of the amount of water separated from the emulsion over a time range of $0,0.5,1,2,6,12$, and $24 \mathrm{~h}$. Between the readings, the emulsion samples were allowed to settle in a thermal water bath at a temperature of $60^{\circ} \mathrm{C}$. All emulsion preparations and measurements were carried out at $60^{\circ} \mathrm{C}$ to emulate the temperature of the field separator.

\section{Testing and characterization}

Experimental studies were conducted to identify the mechanism by which the emulsion is affected by the chemicals. The interfacial tension properties between crude oil and the solutions of alkali and surfactant were measured using a spinning drop tensiometer. The viscosity of polymer solutions was measured using Anton Paar's rotational rheometer. Micrographic images of the emulsion samples were captured using cross-polarization Microscopy to validate the findings from the stability study.

\section{Measurement of emulsion stability}

Investigating the effect of natural emulsifiers and added chemicals on the crude oil emulsion could be achieved by conducting a stability test. The stability of the emulsion is indicated by the separation of the phases, compromising it over time. In other words, it is indicated by the amount of water separated; the larger the water separated volume, the lower the emulsion stability (Sun et al. 2017). The samples' emulsion stability was evaluated using the TurbiScan test (TurbiScan Lab. Formulation) as described by Kowalska and Żbikowska (2016). Emulsions of the various samples in the glass cells were scanned by a pulsed near the infrared light source and two synchronous detectors. The transmission detectors received the incident beam passing through the samples, indicating the separated water zone, while the light scattered was received by backscattering detectors indicating the unresolved emulsion layer. In the end, the results were presented as the dependency of transmitted and backscattered light intensity as a function of sample height.

\section{Measurement of interfacial tension}

The interfacial tension (IFT) properties between crude oil and the solutions of alkaline and surfactant were measured using a spinning drop tensiometer. The interfacial tension measurements were performed using SVT $20 \mathrm{~N}$ spinning drop tensiometer from Data Physics Company, Germany. All the experimental interfacial tension results were collected using a fast image processing system with the appropriate software. The measurement was done automatically, and the interfacial tensions were recorded. The tensiometer was calibrated before each measurement cycle to ensure accurate results.

\section{Viscosity measurement of polymer solutions}

The effect of polymer concentration on the viscosity of brine was measured using MCR 302 Anton Paar's rotational rheometer at a shear rate ranging between 0 and 1000 $1 / \mathrm{s}$ and a temperature of $60{ }^{\circ} \mathrm{C}$. The device used a parallel plate measuring system and Peltier temperature control for heating. The viscosity of polymer solutions of concentration ranging between 0 to $800 \mathrm{ppm}$ was measured multiple times, and the average value was taken.

\section{Droplet size analysis for the dispersed water droplet}

The size of dispersed droplets was found to influence other properties in the emulsion, such as its stability and rheology (Kokal 2005). This analysis was done to monitor the changes in water droplet size as a function of chemical concentration. Monitoring the changes of water droplet sizes as the chemical composition differs gives information on the stability of the emulsion system. The measurements were done using BX53 Olympus Cross-Polarization Microscopy (CPM), which employs a 24 pins CMOS colored camera with a frame rate range of 10 to 49 images per second. The CPM is supported by a hot-stage (HS82) control unit (HS1) 
from Mettler Toledo. The measurements were conducted under a $10 \times$ magnification lens at $60{ }^{\circ} \mathrm{C}$.

\section{Results and discussion}

\section{Effect of indigenous stabilizing components}

Figure 1 shows the emulsion samples after $24 \mathrm{~h}$ of settling separation test. Case 1 represents the effect of natural emulsifiers alone as alkaline, surfactant, and polymer are absent in this case. The results revealed that only $40 \%$ of the original water volume was separated while the remaining water was trapped within the unresolved emulsion layer, also known as the rag layer (Khatri et al. 2011). The rag layer makes up to $50 \%$ of the emulsion sample volume of Case 1 . The existence of the rag layer after the separation process ceased indicates that the separation process was aborted due to termination in the droplet coalescence (merging) process. The behavior was attributed to the effect of indigenous stabilizing components such as asphaltenes, wax, resins, saturates, aromatics and organic and inorganic solids. The interfacially active components are believed to come mostly from asphaltenes and resins of the crude oil (Li et al. 2002; Sjoblom 2005). Asphaltene and resins have a hydrophilic and hydrophobic nature that accumulates at the oil-water interface, forming an interfacial film around the water droplets. The emulsion was then stabilized as the water droplets become unable to coalesce and settle, so they favor remaining in the rag layer. Wax further increases the stability of the emulsion by precipitating at the oil-water interface, strengthening the interfacial film's rheological properties (Sjoblom 2005). The synergistic effect of the indigenous stabilizers was clear to cause the stability of emulsion in the absence of chemicals.

\section{Effect of alkali concentration}

\section{Interfacial tension}

The interfacial tension (IFT) between the crude oil and alkali solutions is shown in Fig. 2. Noticeably, the interfacial tension between the crude oil and the aqueous phase has increased from 9.66 to $12.2 \mathrm{~m} \mathrm{~N} / \mathrm{m}$ in the presence of 250 ppm alkali. However, when the alkali concentration increased above $250 \mathrm{ppm}$, the interfacial tension decreased until it eventually became the lowest at $8.4 \mathrm{~m} \mathrm{~N} / \mathrm{m}$ for an alkali concentration of $1000 \mathrm{ppm}$. The observations indicated that the interfacially active components (in-situ surfactant), formed by the reaction between the alkali and the crude oil acids, have partially replaced the natural emulsifiers at the oil-water interface. When the alkali concentration was below $250 \mathrm{ppm}$, the in-situ surfactant that replaced the indigenous emulsifiers, was less interfacially active than that of the indigenous emulsifiers. Thus, interfacial tension was increased.

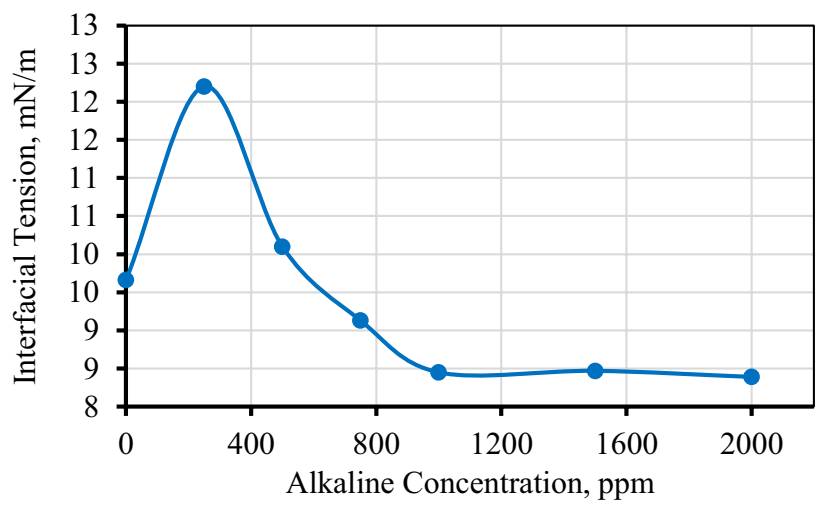

Fig. 2 Effect of alkali concentrations on interfacial tension
Fig. 1 Base case emulsion samples after $24 \mathrm{~h}$ of settling test

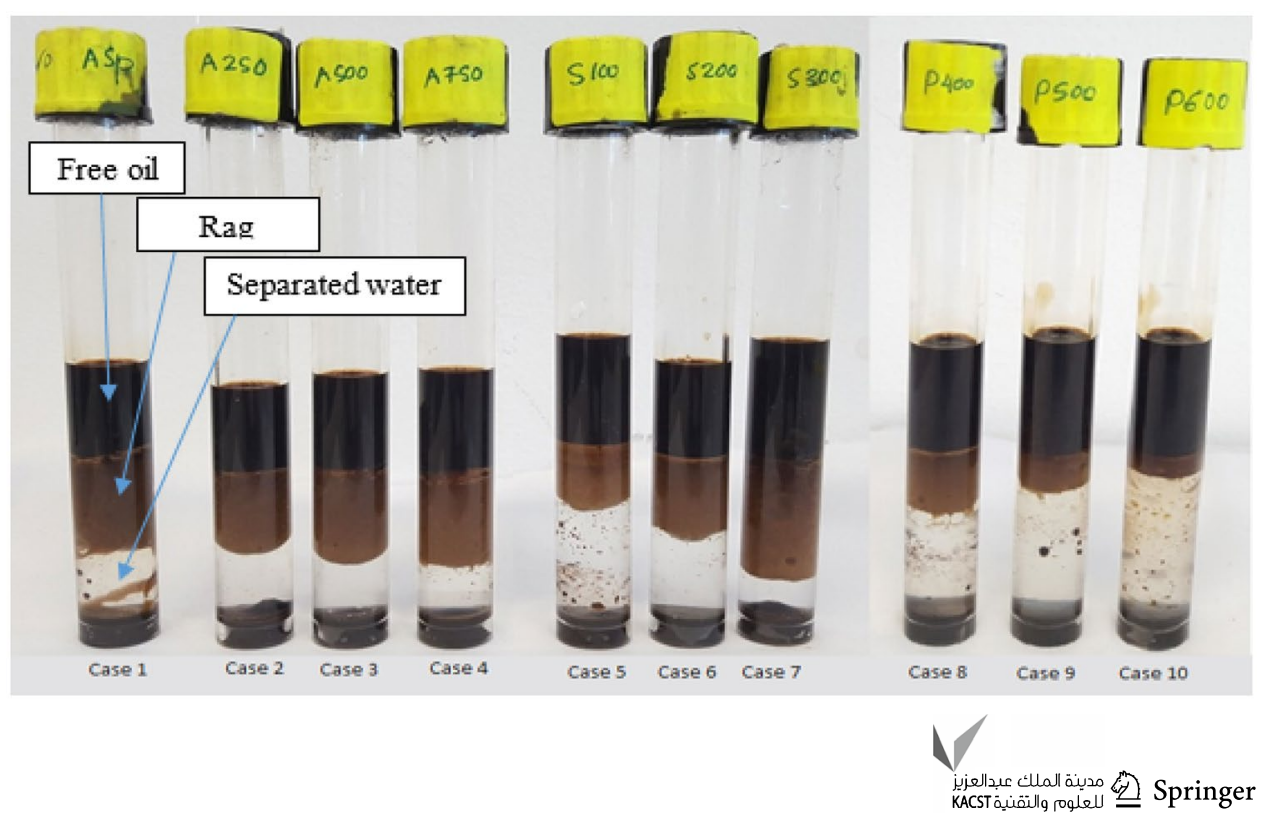


Conversely, when the alkali concentration exceeds $250 \mathrm{ppm}$, the in-situ surfactant becomes more interfacially active as more active components are produced. Therefore, the interfacial tension between oil and water decreases. Similar findings were reported in Sjoblom, (2005). The interfacial tension behavior directly influences the stability of emulsion as the stability increases when the interfacial tension between oil and water decreases (Belhaj et al. 2021b; Deng et al. 2005).

\section{Stability of emulsion}

The effect of alkali on emulsion stability was investigated. The stability was measured in terms of water separation and rag layer volume. The results indicated that emulsion stability increases as alkali concentration increases, as shown in Fig. 3. In the absence of alkali, the natural emulsifiers have a significant influence and only $40 \%$ of the original water was separated, and $51 \%$ of the rag layer remained unresolved. Initially, when alkali concentration increased from 0 to $250 \mathrm{ppm}$, the water separation increased the rag layer volume decreased. However, the subsequent increase in alkali concentration has decreased water separation and increased the unresolved rag layer. Overall, it was observed that alkali does not significantly influence the emulsion behavior within the envelope of the experimental conditions.

\section{Droplet size analysis}

Micrograph images of the dispersed water droplets were captured using CPM. The images were then processed using the equipment's software to measure the size of a minimum of 100 droplets for each emulsion sample. The measured droplet diameters were then normally distributed using Excel software to produce droplet size distribution curves. The graphs illustrate a clear picture of the effect of chemicals on water droplet sizes and distribution. The peak point of the

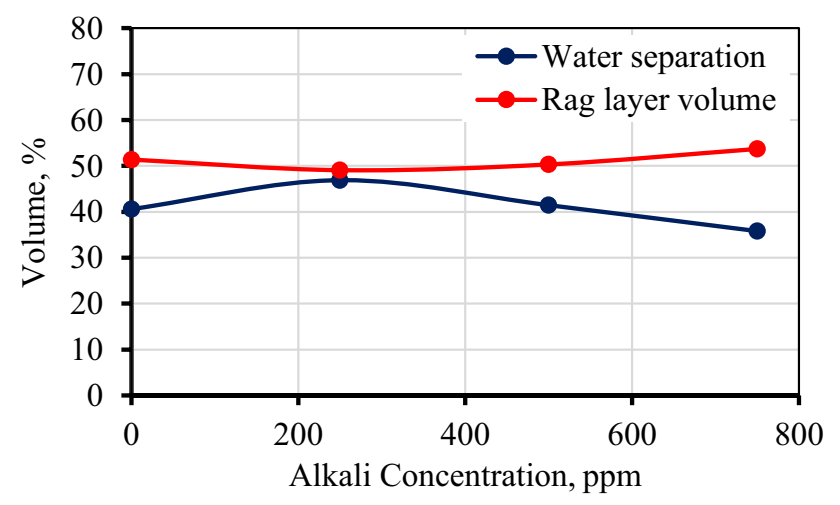

Fig. 3 Effect of alkali on water separation and rag layer volume after separation for $24 \mathrm{~h}$ curve represented the mean water droplet diameter. Larger water droplets were distributed on the right side of the curve, while the smaller droplets were distributed along the left side of the curve. The effect of alkali concentration on water droplet size is shown in Fig. 4. Water droplet size decreases as alkali concentration increases. Initially, the droplet size distribution range becomes wider as alkali concentration increases from 0 to $250 \mathrm{ppm}$. However, it becomes narrower eventually at an alkali concentration of $750 \mathrm{ppm}$.

Figure 5 shows the water changes in mean droplet diameter as a function of alkali concentration. The results explain and support the findings from the stability study. As alkali concentration increased above $250 \mathrm{ppm}$, the interfacial tension between oil and water decreased, deterring smaller water droplets from merging. Thus, the water separation reduced, and rag layer volume increased. Consequently, the quantity of smaller size droplets was growing as alkali concentration increased. The emulsion stability is directly related to the droplet size as smaller droplets find it hard to coalesce and separate from the emulsion layer (Kang and Wang 2001).

\section{Effect of surfactant concentration}

\section{Interfacial tension}

Figure 6 shows the interfacial tension between crude oil and AOS surfactant solution at different concentrations. The addition of the surfactant reduced the IFT significantly. However, at or below 100 ppm of surfactant concentration, the interfacial tension between the crude oil and aqueous phase increased as compared to the case when the surfactant was not introduced. The increase in IFT by adding $100 \mathrm{ppm}$ of the surfactant was due to the presence of bound molecules (surfactant) at the oil/water interface which hampers the coalescence of the droplets. Thus, the coalescence profile depends on the size distribution of the droplets and the amount of surfactant adsorption on the

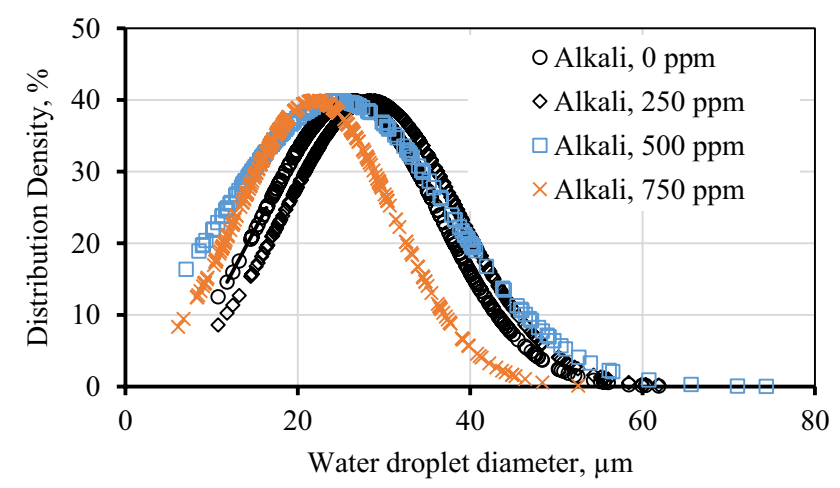

Fig. 4 Effect of alkali on water droplet size distribution 
Fig. 5 Micrographs of alkali effect on the water mean droplet diameter
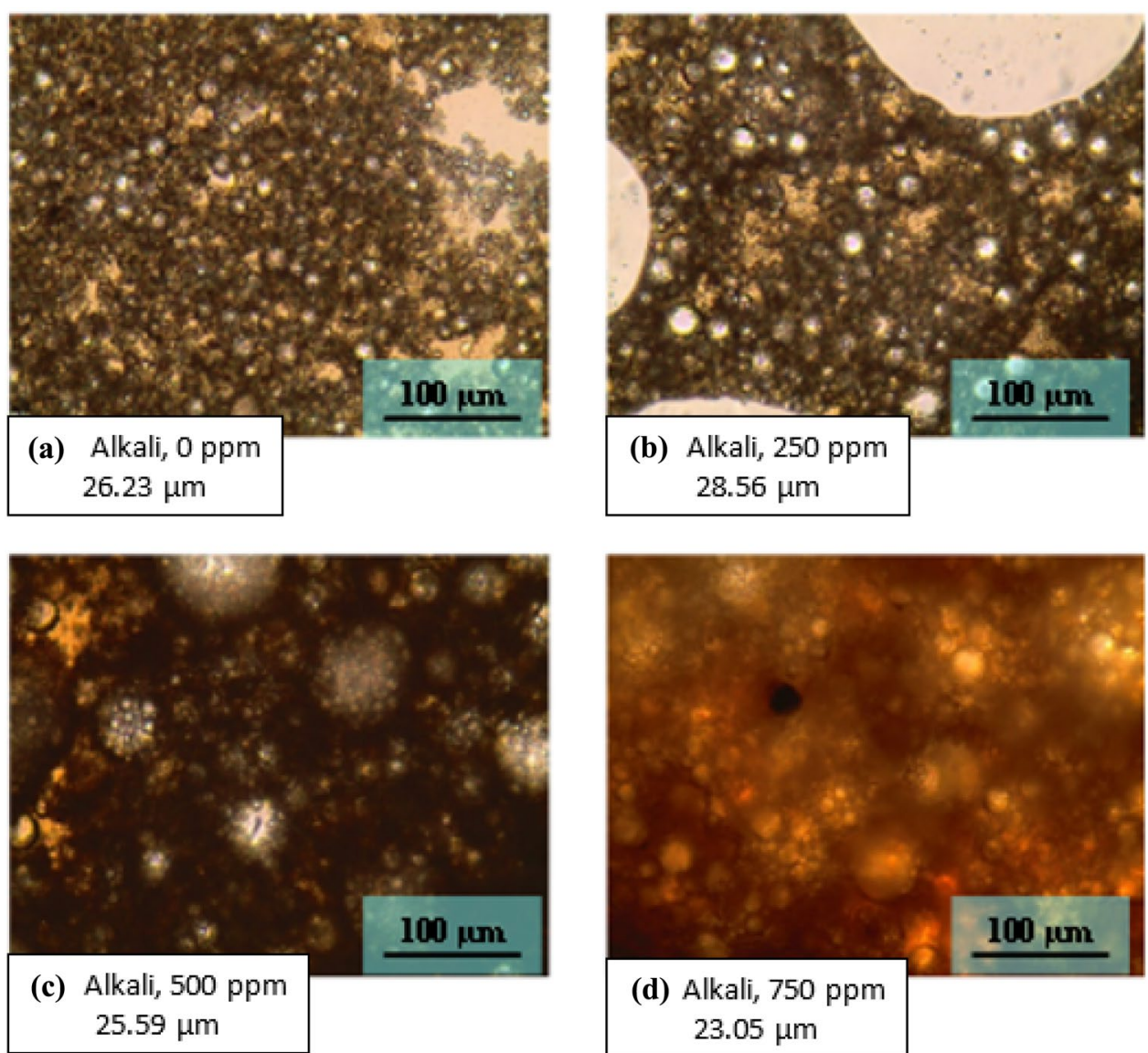

(d) Alkali, $750 \mathrm{ppm}$ $23.05 \mu \mathrm{m}$

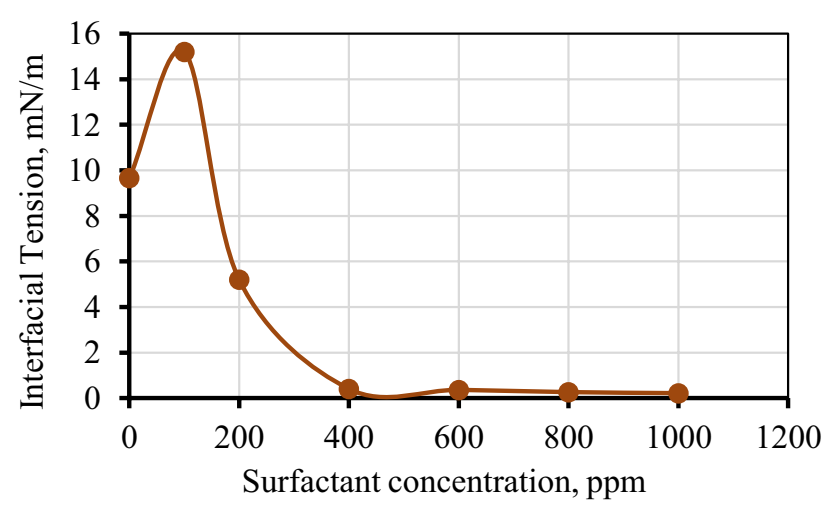

Fig. 6 Effect of different surfactant concentrations on interfacial tension

oil/water interface (Belhaj et al. 2020b). The presence of bound molecules can affect all the mechanisms of the sedimentation process and, therefore, provide major insight into the destabilization of the emulsion (Abeynaike et al. 2012). Pal (2014) reported an increase in the dispersed phase of the $\mathrm{O} / \mathrm{W}$ emulsion with surfactant which was explained by the increase in the energy destruction rate significantly due to an increase in the emulsion viscosity.
The reason behind the stabilization of the emulsion with surfactant addition is that at a higher surfactant concentration, the solubilization of oil and water makes it possible to increase the oil recovery (Hirasaki et al. 2010). This indicated that $100 \mathrm{ppm}$ of surfactant was not as interfacially active as the indigenous emulsifiers that it replaced. Thus, the interfacial tension increased. Above $100 \mathrm{ppm}$ of AOS solution, the interfacial tension between crude oil and the aqueous solution has decreased significantly, indicating an accumulation of more surfactant molecules at the area between oil-water phases.

AOS as an anionic surfactant consists of a negatively charged head group that is polar (hydrophilic) and a positively charged tail group that is non-polar (hydrophobic). The hydrophilic head of the surfactant extends into the water phase, and the hydrophobic tail extends into the oil phase, therefore changing the interfacial properties between the oil and water phase (Wang et al. 2011; Belhaj et al. 2020c; Hussien et al. 2019). As surfactant concentration increased above $100 \mathrm{ppm}$, the interfacial tension decreased sharply until $400 \mathrm{ppm}$. Beyond $400 \mathrm{ppm}$, the interfacial tension was very low. At less than $0.5 \mathrm{~m} \bullet \mathrm{N} / \mathrm{m}$, the surfactant concentration has little effect on the interfacial tension. 


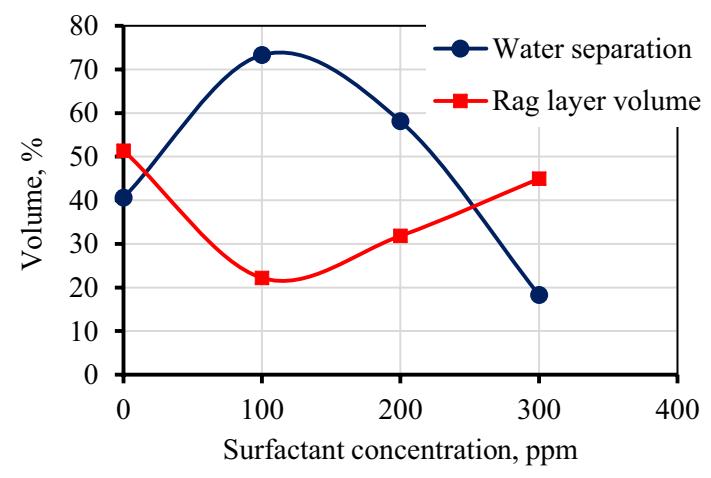

Fig. 7 Effect of surfactant on water separation and rag layer volume after separation for $24 \mathrm{~h}$

\section{Stability of emulsion}

Figure 7 represents the effect of different surfactant concentrations on water separation and rag layer volume. Compared to alkali, surfactant had a more significant influence on the emulsion behavior observed on both rag layer and water separation. The addition of surfactant has increased emulsion stability in which water separation volume decreased as surfactant concentration increased. When 100 ppm of surfactant was loaded to the emulsion system, a substantial change was observed in the emulsion behavior. The water separation volume has increased from 40 to $73.3 \%$ resulting in a reduction in rag layer volume from 51 to $22 \%$.

A similar trend was observed in terms of interfacial tension behavior (Fig. 7). Increasing surfactant concentration from 0 to $100 \mathrm{ppm}$ leads to increased interfacial tension from 9.66 to $15.2 \mathrm{~m} \bullet \mathrm{N} / \mathrm{m}$, respectively. The behaviors are interrelated, as when interfacial tension between oil and water was elevated, the water droplet coalescence was promoted. Therefore, water separation volume was increased. That implies a reduction in the volume of the rag layer as a smaller amount of water droplets were trapped within the rag layer. As surfactant concentration increased above 100 ppm, water separation was observed to reduce while the rag layer volume increased. The more surfactant is supplied into the emulsion system, the more emulsifying agents (surfactant molecules) accumulate at the oil-water interface.

For this reason, the interfacial tension between oil and water has declined, as the accumulation of surfactant molecules has further reduced the intermolecular interaction between water droplets. Therefore, the water droplets have a weaker ability to approach and coalesce, reducing the volume of water separation from the emulsion and increasing the rag layer volume. At 300 ppm surfactants, the water separation reduced to $18 \%$, leaving $44 \%$ of the unresolved rag layer. The stability of the emulsion was not expected to undergo significant changes above 300 ppm of surfactant concentration as there were minor changes in interfacial tension above the mentioned value.

\section{Droplet size analysis}

Figure 8 shows the surfactant effect on water droplet size and distribution. Initially, the droplet size distribution expands as the surfactant concentration increases from 0 to $100 \mathrm{ppm}$. Then, the droplet size distribution becomes narrower when surfactant concentration was increased from 100 to $300 \mathrm{ppm}$.

Likewise, the mean droplet diameter also reduces as surfactant concentration increases from 100 to $300 \mathrm{ppm}$, as shown in Fig. 9. The behavior matches the observations from the interfacial tension and stability test results. When surfactant concentration was increased up to $100 \mathrm{ppm}$, the water droplet size increases due to higher interfacial tension between oil and water, which permits the smaller water droplets to merge and form bigger droplets. Consequently, water separation was enhanced, and rag layer volume was degraded, indicating the reduced stability of the emulsion sample. Conversely, above 100 ppm of surfactant, the water droplet size reduces due to lower the interfacial tension between oil and water, which subdues the ability of smaller droplets to merge and separate from the emulsion. Hence, the emulsion was more stable as less water separated from the emulsion and more rag layer volume remained unresolved. Similar observations have been discussed in Kang and Wang (2001).

\section{Effect of polymer concentration}

\section{Viscosity}

The effect of polymer concentration on the viscosity of synthetic produced water is shown in Fig. 10. The viscosity was measured at a shear rate ranging between 0 and $10001 / \mathrm{s}$ at $60{ }^{\circ} \mathrm{C}$. The results indicate that the increase in shear rate

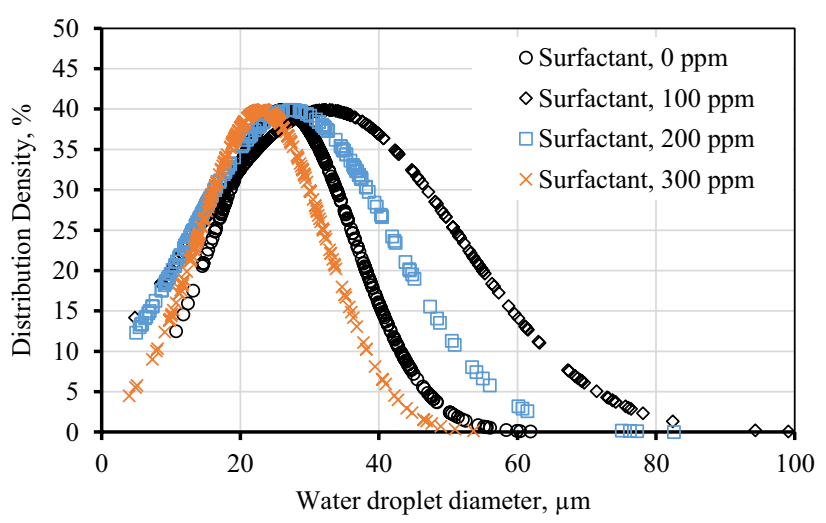

Fig. 8 Effect of surfactant on water droplet size distribution 
Fig. 9 Micrographs of surfactant effect on water droplet mean diameter
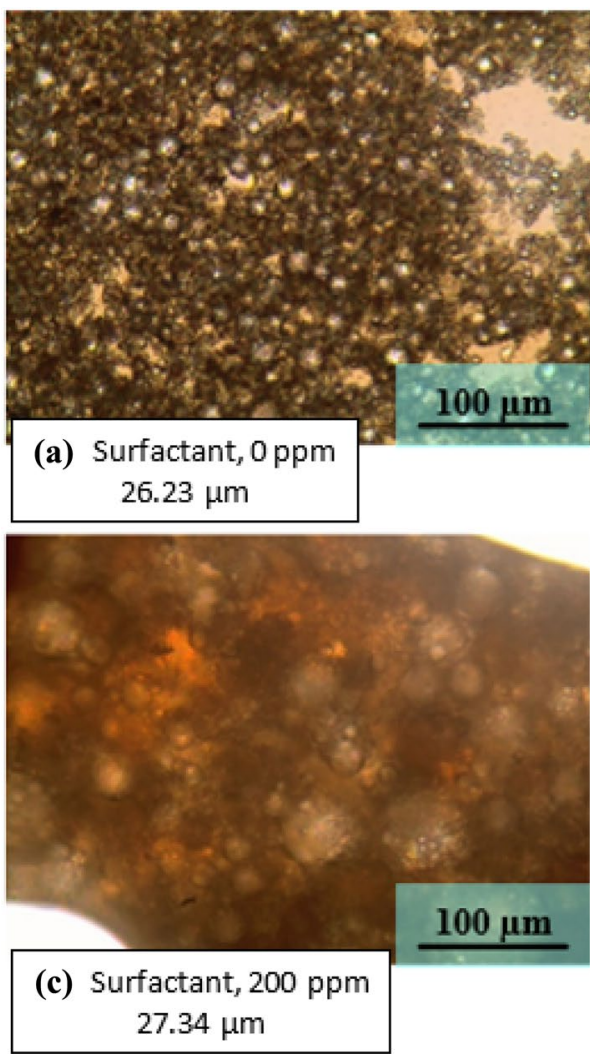
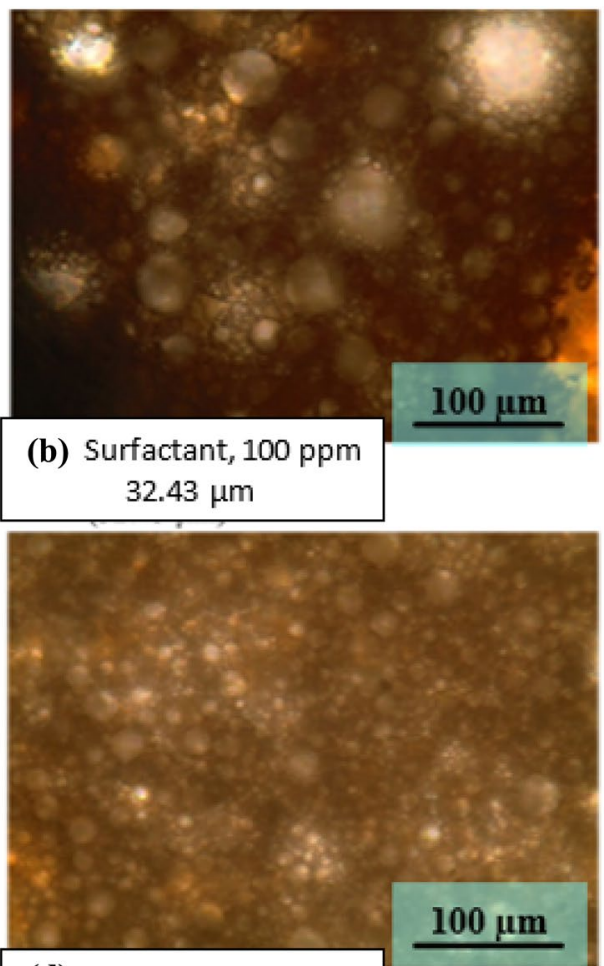

(d) Surfactant, $300 \mathrm{ppm}$ $23.12 \mu \mathrm{m}$

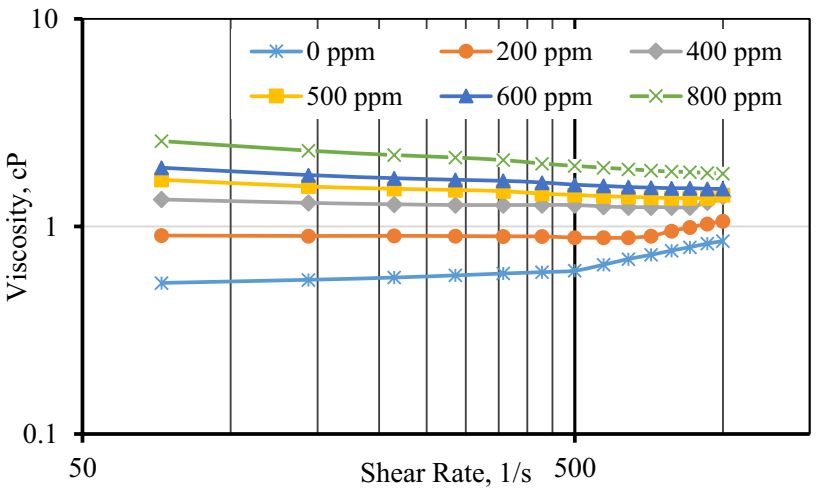

Fig. 10 Effect of different polymer concentrations on the viscosity of aqueous phase

increases the viscosity up to $400 \mathrm{ppm}$ of polymer concentration. However, the viscosity undergoes insignificant changes with the increase in shear rate. On the contrary, the viscosity reduces as the shear rate increases when polymer concentration increases above $400 \mathrm{ppm}$. This observation suggests that GLP100 is a low-molecular-weight (LMW) polymer as high-molecular-weight (HMW) polymers are known to be highly shear sensitive (Wang et al. 2011; Weatherill 2009).

Increasing the polymer concentration has a clear effect on increasing the aqueous phase viscosity. Hence, the stability of the emulsion was expected to be affected by the presence of polymer as a function of the viscosity effect. Stock's law states that the sedimentation velocity is inversely proportional to the viscosity of the aqueous phase of an emulsion, which implies that the emulsion stability could be increased by increasing the aqueous phase viscosity. However, the intensity of viscosity effect on stabilizing the emulsion depends on the molecular weight of the polymer (Wang et al. 2011). HMW polymers significantly increase the viscosity of the aqueous phase at a lower concentration than LMW polymers. The viscosity effect for HMW and LMW polymers appears when the polymer concentration reaches a critical concentration point. Below the critical concentration point, the polymer acts as a de-emulsifier and promotes droplet flocculation, reducing the emulsion's stability (Wang et al. 2011). In this case, the stability of the emulsion was expected to decline as the polymer concentration increases up to the critical concentration level, then upsurges when the polymer concentration was above that critical level. Emulsion stability tests were conducted to examine the behavior. Khatibi et al. 2016 have currently presented experimental measurements on the effect of salt on the rheological properties of Non-Newtonian fluids. Their results have the same trend on the change in viscosity as of the results obtained in the current study, as shown in the Fig. 11. The pure water, water with $5 \%$ wt salt, and water with $20 \%$ wt $\mathrm{KCOOH}$ all show a slight increase in the viscosity with an increase of shear rate. However, a higher concentration of salt, the

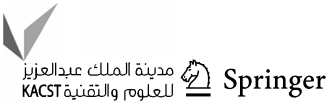




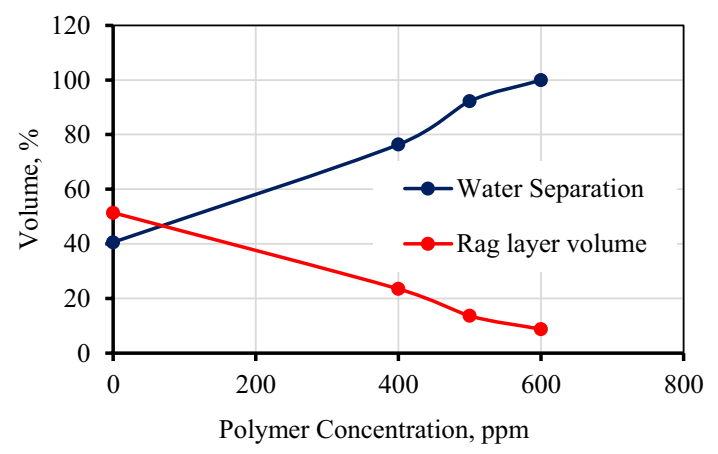

Fig. 11 Effect of polymer concentrations on water separation and rag layer volume after separation for $24 \mathrm{~h}$

experiment temperature, and the type of additive to water all affect the produced brines' behavior. It seems interesting to further investigate the viscosity of brines from different oil wells at various testing temperatures and then with different added polymers and/or salt. Researchers who worked and published in the field also recommend that there is still a debate to finalize the conclusion of polymer on the stabilization of emulsion (Koh 2015; Seright 2017).

\section{Stability of emulsion}

The effect of different polymer concentrations on rag layer volume and water separation is shown in Fig. 11. The results revealed that as polymer concentration increased, the amount of water separated from the emulsion increased. Correspondingly, the rag layer reduced from 50 to 23,13 and $8 \%$ for polymer concentrations of $0,400,500$, and 600 ppm, respectively. The behavior shown in Fig. 10 demonstrates that as polymer increases aqueous phase viscosity, the strength of the interfacial film surrounding the water droplets was weakened, which allowed the water droplets to merge and separate from the emulsion to the free water zone. Therefore, the amount of water separation was enhanced. At $600 \mathrm{ppm}$ polymer, $99 \%$ of the water separated from the emulsion. Similar behavior was discussed by Deng et al. (2005).

The results suggest that the investigated range of polymer concentrations falls below the critical concentration point above which polymer begins to elevate the emulsion stability as a function of increasing viscosity (Wang et al. 2011). The findings also support the assumption that GLP100 polymer is a low-molecular-weight (LMW) polymer. Similar behavior was recorded as LMW of partially hydrolyzed polyacrylamide (HPAM) polymer destabilized the emulsion when its concentration was below $800 \mathrm{ppm}$. At the same time, highmolecular-weight (HMW) HPAM destabilizes the emulsion when its concentration was not more than 300 ppm. From the observations, it could be concluded that the presence

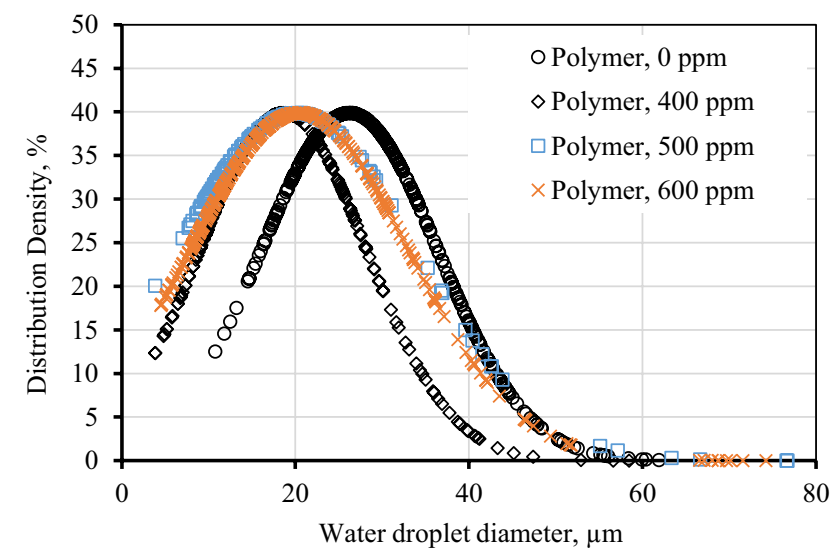

Fig. 12 Effect of polymer on water droplet size and distribution

of polymer in the emulsion system would function as a deemulsifier that promotes the separation of water and reduces the emulsion stability under the investigated conditions.

\section{Droplet size analysis}

The effect of polymer on water droplet size is illustrated in Fig. 12. The observations demonstrate interesting findings regarding the polymer exhibiting complicated behavior when added to the emulsion system.

At zero ppm of polymer, the water droplet sizes range from 10 to $63 \mu \mathrm{m}$. When polymer concentration increases from 0 to $400 \mathrm{ppm}$, the droplet distribution range becomes narrower, expanding to the left side of the curve to cover between 3 and $58 \mu \mathrm{m}$. However, the density of larger droplets was noticed to decrease significantly. For instance, at $0 \mathrm{ppm}$ polymer, $15 \%$ of the water droplets have a diameter size of $40 \mu \mathrm{m}$, while at $400 \mathrm{ppm}$ only $2.5 \%$ of the water droplets have a size of $40 \mu \mathrm{m}$. However, above $400 \mathrm{ppm}$ of polymer, the droplet size distribution range was expanded to larger droplets ranging between 3 and $76 \mu \mathrm{m}$. The behavior was almost identical when polymer concentration changes from 500 to $600 \mathrm{ppm}$. Additionally, it could be noticed that the mean water droplet diameter was lesser when the polymer was added to the emulsion, as shown in Fig. 13.

The droplet size analysis suggests that the polymer favors the stabilizing emulsion since the water droplets were smaller as the polymer was introduced to the emulsion system. However, this behavior contradicts the findings from the stability study as the polymer exhibited substantial ability in reducing emulsion stability and enhancing water separation. The contradiction could be explained by the results obtained from the stability study. The stability study shows that a high percentage of water was separated as a function of polymer concentration. Correspondingly, the number of water droplets that remained in the rag layer was much lesser in quantity than the previous alkali and surfactant 
Fig. 13 Micrographs of polymer effect on the water mean droplet diameter
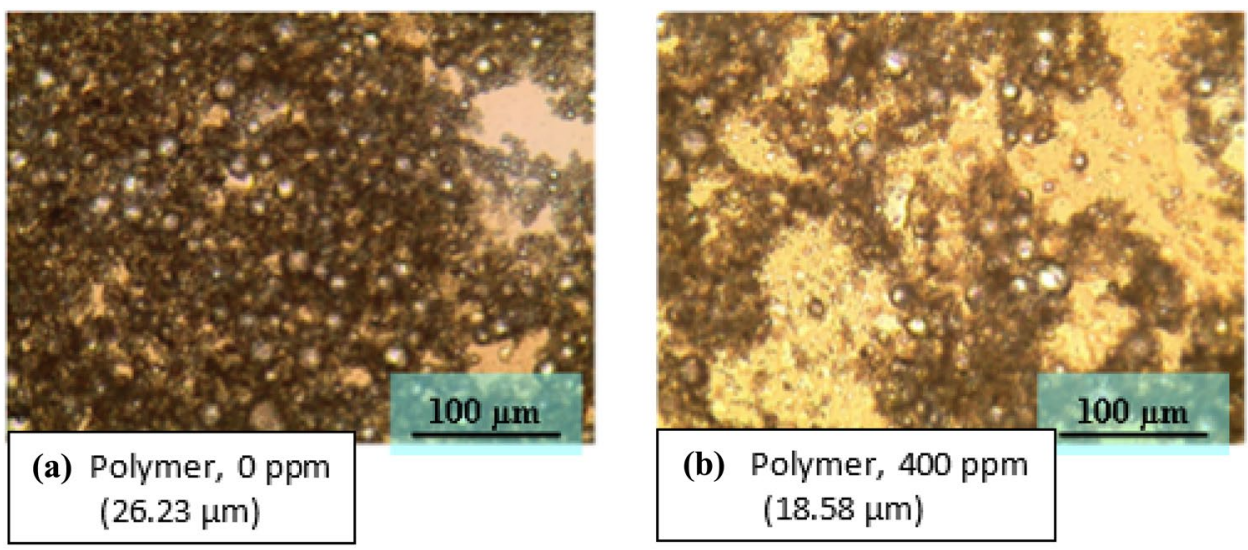

(b) Polymer, $400 \mathrm{ppm}$ $(18.58 \mu \mathrm{m})$

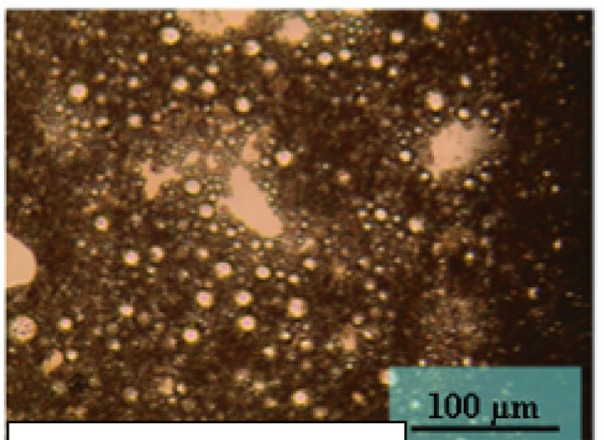

(c) Polymer, $500 \mathrm{ppm}$ $(20.14 \mu \mathrm{m})$

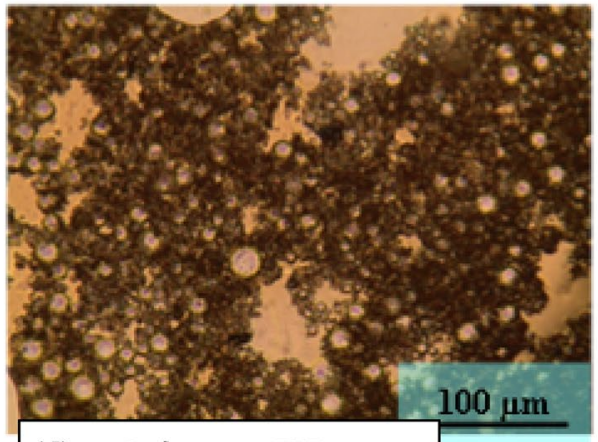

(d) Polymer, $600 \mathrm{ppm}$ $(20.45 \mu \mathrm{m})$ cases. Hence, it is expected for the bigger water droplets to have completely separated from the emulsion and moved from the rag layer to the free water zone. As the polymer is known to promote droplet coalescence (Wang et al. 2011), it is believed that droplets had coalesced and separated from the emulsion leaving behind smaller droplets. Therefore, the density of smaller droplets increases, and the overall water means droplet diameter has reduced.

\section{Conclusion}

Emulsion stability, interfacial tension, and droplet size of various oil/water emulsions with alkali, surfactant, and polymer concentrations were investigated. Low concentrations of alkali and surfactant were expected to assist the separation process. The interfacial tension was increased between oil and water, which facilitated the coalescence of the water droplets. At higher concentrations, alkali and surfactant were not efficient for the separation process. The interfacial tension was reduced between oil and water, making the emulsion much more stable hence, the separation becomes difficult. These findings were reflected in the water droplet size as bigger water droplets were measured at low alkali and surfactant concentrations. In contrary, smaller water droplets were present when a high concentration of alkali and surfactant were added.

The polymer GLP100 acted as an effective de-emulsifier. The analysis of the emulsion with polymer presence has achieved a close to complete separation process. This separation was mainly attributed to the ability of the polymer to promote bigger water droplets to coalesce and eventually separate them from the emulsion. GLP100 is advisable for the enhanced oil recovery process as it increases the oil recovery by improving the sweep efficiency. At the same time, it can assist in countering the effect of surfactant and alkali in the event of a breakthrough. The viscosity behavior of the brine with added polymers has room for further investigation considering the brine composition, the type of polymer and the testing temperature. Further investigations on AS, AP and SP as well as the ASP's combined effect on emulsion stability, droplet size, interfacial tension and rheological properties are highly recommended to support the decision-makers on the EOR implementations with chemical additives.

Acknowledgements The authors acknowledge PETRONAS Research Sdn Bhd (PRSB), Exploration and Production Technology Department (EPTD) for the financial support under grant number EPTD T6-1 and supply of the raw material. Centre of Research for Enhanced Oil Recovery, Universiti Teknologi PETRONAS (COREOR-UTP), is

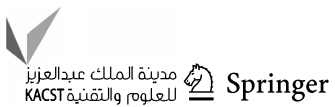


acknowledged for the logistic support to carry out the research and to publish this article. The first author acknowledges UTP for the financial support under the Graduate Assistance (GA) scheme.

Funding This project is funded by PRSB - Malaysia under research grant EPTD-T6-1.

\section{Declarations}

Conflict of interest Here, We confirm that there is no conflict of interest.

Ethical approval Hereby, We assure that this paper has not been previously published and the manuscript reflects our own research and analysis in a truthful and complete manner.

Open Access This article is licensed under a Creative Commons Attribution 4.0 International License, which permits use, sharing, adaptation, distribution and reproduction in any medium or format, as long as you give appropriate credit to the original author(s) and the source, provide a link to the Creative Commons licence, and indicate if changes were made. The images or other third party material in this article are included in the article's Creative Commons licence, unless indicated otherwise in a credit line to the material. If material is not included in the article's Creative Commons licence and your intended use is not permitted by statutory regulation or exceeds the permitted use, you will need to obtain permission directly from the copyright holder. To view a copy of this licence, visit http://creativecommons.org/licenses/by/4.0/.

\section{References}

Abeynaike A et al (2012) The experimental measurement and modelling of sedimentation and creaming for glycerol/biodiesel droplet dispersions. Chem Eng Sci 79:125-137. https://doi.org/10.1016/j. ces.2012.05.036

Ahmed S, Elraies K (2018) Science and technology behind nanoemulsions/Chapter 9 (Microemulsion in Enhanced Oil Recovery). https://www.intechopen.com/books/science-and-technologybehind-nanoemulsions/microemulsion-in-enhanced-oil-recovery

Al-Kayiem HH, Khan JA (2017) Evaluation of alkali/surfactant/polymer flooding on separation and stabilization of water/oil emulsion by statistical modeling. Energy Fuels 31(9):9290-9301. https:// doi.org/10.1021/acs.energyfuels.7b01662

Al-Shuaili K, Guntupalli S, Al-Amri M, Nurzaman Z, Al-Hinai G, Svec Y (2016) Alkali-surfactant-polymer pilot implementation in South Oman: establishing waterflood baseline. In: SPE EOR conference at oil and gas West Asia. Society of Petroleum Engineers. https:// doi.org/10.2118/179752-MS

Argillier JF, Henaut I, Noik C, Viera R, Roca Leon F, Aanesen B (2014) Influence of chemical EOR on topside produced water management. SPE improved oil recovery symposiumhttps://doi. org/10.2118/169067-MS

Belhaj A, Elraies K, Alnarabiji M, Shuhli J, Mahmood S, Ern L (2019a) Experimental investigation of surfactant partitioning in pre-CMC and post-CMC regimes for enhanced oil recovery application. Energies 12:2319. https://doi.org/10.3390/en12122319

Belhaj AF, Elraies KA, Janjuhah HT, Tasfy SF, Yahya N, Abdullah B, Umar AA, Ghanem OB, Alnarabiji MS (2019b) Electromagnetic waves-induced hydrophobic multiwalled carbon nanotubes for enhanced oil recovery. J Pet Explor Prod Technol 9(4):2667-2670. https://doi.org/10.1007/s13202-019-0653-6
Belhaj A, Elraies K, Mahmood S, Tewari R, Elryes A (2020a) A comprehensive surfactant performance assessment in Harsh Malaysian reservoir conditions. In: Offshore technology conference Asia, OTC-30171-MS. https://doi.org/10.4043/30171-MS

Belhaj A, Shuhli J, Elraies K, Mahmood S, Maulianda B, Alnarabiji M (2020b) Partitioning behaviour of novel surfactant mixture for high reservoir temperature and high salinity conditions. Energy 198:117319. https://doi.org/10.1016/j.energy.2020.117319

Belhaj A, Elraies K, Shuhli J, Mahmood S, Tewari R (2020c) Surfactant adsorption evaluation in the presence of crude oil at high reservoir temperature condition. In: Offshore technology conference Asia, OTC-30141-MS. https://doi.org/10.4043/30141-MS

Belhaj AF, Elraies KA, Mahmood SM, Zulkifli NN, Akbari S, Hussien OS (2020d) The effect of surfactant concentration salinity temperature and $\mathrm{pH}$ on surfactant adsorption for chemical enhanced oil recovery: a review. J Pet Explor Prod Technol 10(1):125-137. https://doi.org/10.1007/s13202-019-0685-y

Belhaj A, Elraies K, Alnarabiji M, Abdul Kareem F, Shuhli J, Mahmood S, Belhaj H (2021a) Experimental investigation, binary modelling and artificial neural network prediction of surfactant adsorption for enhanced oil recovery application. Chem Eng J 406:127081. https://doi.org/10.1016/j.cej.2020.127081

Belhaj AF, Elraies KA, Sarma HK, Shuhili JA, Mahmood SM, Alnarabiji MS (2021b) Surfactant partitioning and adsorption in chemical EOR: the neglected phenomenon in porous media. In: SPE/IATMI Asia Pacific oil \& gas conference and exhibition, 12-14 October, SPE-205676-MS. https://doi.org/10.2118/ 205676-MS

Dalmazzone C, Noïk C, Argillier JF (2012) Impact of chemical enhanced oil recovery on the separation of diluted heavy oil emulsions. Energy Fuels 26(6):3462-3469. https://doi.org/10. 1021/ef300083z

Deng S, Yu G, Jiang Z, Zhang R, Ting YP (2005) Destabilization of oil droplets in produced water from ASP flooding. Colloids Surf, A 252(2-3):113-119. https://doi.org/10.1016/j.colsurfa. 2004.09.033

Fortenberry R, Delshad M, Suniga P, Koyassan Veedu F, Wang P, Al-Kaaoud H, Pope G (2016) Interwell ASP pilot design for Kuwait's Sabriyah-Mauddud. In: SPE improved oil recovery conference. Society of Petroleum Engineers. https://doi.org/10. 2118/179703-MS

Hirasaki GJ, Miller CA, Raney OG, Poindexter MK, Nguyen DT, Hera (2010) Separation of produced emulsions from surfactant enhanced oil recovery processes. Energy Fuels 25(2):555-561. https://doi.org/10.1021/ef101087u

Hussien O, Elraies K, Almansour A, Husin H, Belhaj A, Ern L (2019) Experimental study on the use of surfactant as a fracking fluid additive for improving shale gas productivity. J Petrol Sci Eng 183:106426. https://doi.org/10.1016/j.petrol.2019.106426

Ibrahim ZB, Manap AAA, Hamid PA, Hon VY, Lim PH, Wyatt K (2006) Laboratory aspect of chemical EOR processes evaluation for Malaysian oilfields. In: SPE Asia Pacific oil \& gas conference and exhibition. Society of Petroleum Engineers. https:// doi.org/10.2118/100943-MS

Jeirani Z, Jan BM, Ali BS, See C, Saphanuchart W (2014) Preprepared microemulsion flooding in enhanced oil recovery: a review. Pet Sci Technol 32(2):180-193. https://doi.org/10.1080/ 10916466.2011.586968

Kalra A, Venkatraman A, Raney KH, Dindoruk B (2012) Prediction and experimental measurements of water-in-oil emulsion viscosities during alkaline/surfactant injections. Oil and Gas Facilities 1(03):34-43. https://doi.org/10.2118/143992-PA

Kang W, Guo L, Fan H, Meng L, Li Y (2012) Flocculation, coalescence and migration of dispersed phase droplets and oil-water separation in heavy oil emulsion. J Petrol Sci Eng 81:177-181. https://doi.org/10.1016/j.petrol.2011.12.011 
Kang W, Wang D (2001) Emulsification characteristic and de-emulsifiers action for alkaline/surfactant/polymer flooding. In: SPE Asia Pacific improved oil recovery conference. Society of Petroleum Engineers. https://doi.org/10.2118/72138-MS

Kang W, Wang T, Zhang H, Hou X, Zhang X, Zhu T, Chen C, Yang $\mathrm{H}$ (2020) A dynamic scale location monitor method to predict oilfield blockage during water flooding. J Petrol Sci Eng 191:107168. https://doi.org/10.1016/j.petrol.2020.107168

Khan JA, Al-Kayiem HH, Aleem W, Saad AB (2019) Influence of alkali-surfactant-polymer flooding on the coalescence and sedimentation of oil/water emulsion in gravity separation. J Petrol Sci Eng 173:640-649. https://doi.org/10.1016/j.petrol.2018.10.055

Khan JA, Al-Kayiem HH, Aris M (2015) Stabilization of produced crude oil emulsion in the presence of ASP. SPE-174671-MS. https://doi.org/10.2118/174671-MS

Khatibi M, Potokin N, Time RW (2016) Experimental investigation of effect of salts on rheological properties of non-Newtonian fluids. ANNUAL TRANSACTIONS OF THE NORDIC RHEOLOGY SOCIETY, VOL. 24. University of Stavanger

Khatri N, Andrade J, Baydak E, Yarranton H (2011) Emulsion layer growth in continuous oil-water separation. Colloids Surfaces A Physicochem Eng Asp 384(1-3):630-642. https://doi.org/10. 1016/j.colsurfa.2011.05.032

Koh HS (2015) Experimental investigation of the effect of polymers on residual oil saturation. Doctoral dissertation, the university of Texas at Austin, US. http://hdl.handle.net/2152/31624

Kokal SL (2005) Crude oil emulsions: a state-of-the-art review. SPE Prod Facil 20(01):5-13. https://doi.org/10.2118/77497-PA

Kowalska M, Żbikowska A (2016) Study of stability of sesame oil-inwater emulsions determined using an optical analyzer and measurement of particle size and distribution. J Dispersion Sci Technol 37(10):1408-1414. https://doi.org/10.1080/01932691.2015.1111143

Kusumah GS, Vazquez O (2017) Evolution of pH and retention of different alkali species for ASP flooding field applications. In: SPE Bergen one day seminar. Society of Petroleum Engineers. https:// doi.org/10.2118/185886-MS

Li M, Xu M, Ma Y, Wu Z, Christy AA (2002) Interfacial film properties of asphaltenes and resins. Fuel 81(14):1847-1853. https://doi. org/10.1016/S0016-2361(02)00050-9

Li J, Niu L, Lu X (2019) Performance of ASP compound systems and effects on flooding efficiency. J Petrol Sci Eng 178:1178-1193. https://doi.org/10.1016/j.petrol.2019.02.092

Olsen D, Hicks M, Hurd B, Sinnokrot A, Sweigart C (1990) Design of a novel flooding system for an oil-wet Central Texas carbonate reservoir. In: SPE/DOE enhanced oil recovery symposium. Society of Petroleum Engineers. https://doi.org/10.2118/20224-MS

Onyekonwu M, Akaranta O (2016) Alkaline-surfactant flooding in Niger-Delta: an experimental approach. In: SPE Nigeria annual international conference and exhibition. Society of Petroleum Engineers. https://doi.org/10.2118/184271-MS

Othman M, Chong MBO, Sai RM, Zainal S, Yaacob AA, Zakaria MS (2007) Meeting the challenges in alkaline surfactant pilot project implementation at Angsi field, offshore Malaysia. In: Offshore Europe. Society of Petroleum Engineers. https://doi.org/10.2118/109033-MS

Pal R (2014) Exergy destruction in pipeline flow of surfactant-stabilized oil-in-water emulsions. Energies 7:7602-7619. https://doi. org/10.3390/en7117602

Pal N, Kumar S, Bera A, Mandal A (2019) Phase behaviour and characterization of microemulsion stabilized by a novel synthesized surfactant: Implications for enhanced oil recovery. Fuel 235:9951009. https://doi.org/10.1016/j.fuel.2018.08.100

Riswati SS, Bae W, Park C, Permadi AK, Efriza I, Min B (2019) Experimental analysis to design optimum phase type and salinity gradient of Alkaline Surfactant Polymer flooding at low saline reservoir. J Pet Sci Eng 173:1005-1019. https://doi.org/10.1016/j. petrol.2018.09.087
Rohilla N, Ravikiran R, Carlisle CT, Jones N, Davis MB, Finch KB (2016) Design of a robust ASP formulation for clay rich and moderate permeability sandstone reservoir: from laboratory to single well chemical tracer test in the field. In: SPE improved oil recovery conference. Society of Petroleum Engineers. https://doi.org/ 10.2118/179678-MS

Sabzabadi A, Amirrudin F, Vai Yee H, Johar MJ (2013) Managing chemical flooding, and by-products with produced water re-injection (PWRI) system in offshore environment. In: SPE enhanced oil recovery conference. Society of Petroleum Engineers. https:// doi.org/10.2118/165294-MS

Saxena N, Goswami A, Dhodapkar P, Nihalani M, Mandal A (2019) Bio-based surfactant for enhanced oil recovery: interfacial properties, emulsification and rock- fluid interactions. J Petrol Sci Eng 176:299-311. https://doi.org/10.1016/j.petrol.2019.01.052

Sayed A, Olesen K, Sattar A, Sølling T, Alyafei N (2019) The effect of organic acids and salinity on the interfacial tension of n-decane/ water systems. J Petrol Sci Eng 173:1047-1052. https://doi.org/ 10.1016/j.petrol.2018.10.097

Seright RS (2017) How much polymer should be injected during a polymer flood? Review of previous and current practices. In: IOR 2017 - 19th European symposium on improved oil recovery. https://doi.org/10.3997/2214-4609.201700317

Sharma H, Lu J, Weerasooriya UP, Pope GA, Mohanty KK (2016) Adsorption in chemical floods with ammonia as the alkali. In: SPE improved oil recovery conference. Society of Petroleum Engineers. https://doi.org/10.2118/179682-MS

Sheng J (2014) Critical review of low-salinity waterflooding. J Petrol Sci Eng 120:216-224. https://doi.org/10.1016/j.petrol.2014.05. 026

Sheng J (2015) Status of surfactant EOR technology. Petroleum 1:97105. https://doi.org/10.1016/j.petlm.2015.07.003

Sheng J (2011) Modern chemical enhanced oil recovery: theory and practice. Gulf Professional Publishing.https://doi.org/10.1017/ CBO9781107415324.004

Sjöblom J, Aske N, Auflem IH, Brandal Ø, Havre TE, Sæther $\varnothing$, Kallevik H (2003) Our current understanding of water-in-crude oil emulsions: recent characterization techniques and high pressure performance. Adv Colloid Interface Sci 100:399-473. https://doi. org/10.1016/S0001-8686(02)00066-0

Sjoblom J (2005) Emulsions and emulsion stability. Surfactant Science Series/61, CRC Press

Southwick JG, van den Pol E, van Rijn CH, van Batenburg DW, Boersma D, Svec Y, Raney K (2016) Ammonia as alkali for alkaline/surfactant/polymer floods. SPE J 21(01):10-21. https://doi. org/10.2118/169057-PA

Sun N, Jing J, Jiang H, An Y, Wu C, Zheng S, Qi H (2017) Effects of surfactants and alkalis on the stability of heavy-oil-in-water emulsions. SPE J 22(01):120-129. https://doi.org/10.2118/181742-PA

Wang B, Wu T, Li Y, Sun D, Yang M, Gao Y, Li X (2011) The effects of oil displacement agents on the stability of water produced from ASP (alkaline/surfactant/polymer) flooding. Colloids Surf, A 379(1-3):121-126. https://doi.org/10.1016/j.colsurfa.2010.11.064

Weatherill A (2009) Surface development aspects of alkali-surfactantpolymer (ASP) flooding. International petroleum technology conference. International Petroleum Technology Conferencehttps:// doi.org/10.2523/IPTC-13397-MS

Yekeen N, Padmanabhan E, Idris A, Ibad S (2019) Surfactant adsorption behaviors onto shale from Malaysian formations: influence of silicon dioxide nanoparticles, surfactant type, temperature, salinity and shale lithology. J Petrol Sci Eng 179:841-854. https://doi. org/10.1016/j.petrol.2019.04.096

Publisher's Note Springer Nature remains neutral with regard to jurisdictional claims in published maps and institutional affiliations.

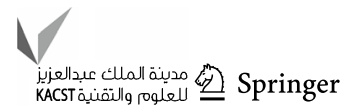

